\title{
Folates and prevention of disease
}

\author{
Anne M Molloy ${ }^{1}$ and John M Scott ${ }^{2 *}$ \\ ${ }^{1}$ Department of Clinical Medicine, Trinity College Dublin, Dublin 2, Ireland: ${ }^{2}$ Department of Biochemistry, Trinity \\ College Dublin, Dublin 2, Ireland
}

\begin{abstract}
Research in the past decade has established that low or inadequate folate status may contribute to congenital malformations and the development of chronic disease in later life. Using an evidence based approach, there are clear guidelines for recommending folic acid supplementation or fortification in certain disease conditions but further proof of its efficacy is required in other circumstances.

There is conclusive evidence that maternal periconceptional supplementation with folic acid prevents the majority of NTDs, probably by overcoming one or more genetically inherited metabolic blocks in folate dependent enzymes. Public health efforts to advise women to increase their folate intake have not been successful. As a result, the U.S. government passed legislation to have all flour fortified with folic acid. This intervention has had a dramatic effect on folate status in the U.S. To date, countries of the EU have not adopted mandatory fortification policies.

The amino acid homocysteine is an essential intermediate in folate metabolism. Substantial evidence indicates that elevated plasma homocysteine is an independent risk factor for heart disease and stroke. Plasma homocysteine levels can be reduced by folic acid supplements. A food fortification policy would probably be an effective population strategy to reduce plasma homocysteine. However, many experts believe that this would be premature without first showing that such reduction would cause a decrease in the prevalence of cardiovascular disease.

The contribution of folate to cancer risk is not well defined although there is reasonable evidence to implicate low folate status in the specific case of colorectal cancer. In particular, long-term folic acid supplementation may reduce risk of colorectal cancer substantially.

Various mental disorders including Alzheimer's Disease have been associated with low folate status or elevated plasma homocysteine. While it is hard to determine if this is cause or effect, there is little doubt that if it were true then low dose folic acid intervention would be highly effective.
\end{abstract}

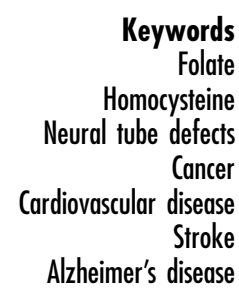

\section{Introduction}

It has long been known that the folate cofactors are important for cell proliferation, because of their essential role in DNA synthesis ${ }^{1}$. The most devastating effects of severe prolonged folate deficiency occur in the rapidly dividing cells of the bone marrow and digestive tract. The importance of folates in maintaining a supply of methyl groups for the remethylation of homocysteine and the subsequent use of these to methylate a wide variety of biological components through S-adenosylmethionine (AdoMet) is less apparent. However, in the past few years the negative effects of elevated plasma homocysteine have been connected to conditions as widely disparate as complications of pregnancy, cardiovascular disease and neuropsychiatric dysfunction. Inadequate or marginal folate status can now be regarded as a major contributing factor to risk of congenital malformations as well as the development of chronic disease in later life ${ }^{2}$. The evidence for this ranges from conclusive in the case of neural tube defects to persuasive in the case of cardiovascular disease and tentative in the case of some forms of cancer and neurological disease.

\section{Neural tube defects}

\section{Burden of disease}

(a) Epidemiological analysis of the disease within the EU Spina Bifida and other neural tube defects (NTDs) are among the most common of all birth defects. Failure to properly close the neural plate over the spinal column results in spina bifida, with various levels of disability depending upon how incomplete the closure. Failure of 
the neural plate to form the cranium produces the condition called anencephaly which is incompatible with life. NTDs are known to result from a genetic predisposition interacting with nutrition. It is now clear that the key nutrient involved in the proper closure of the neural tube is the vitamin folate ${ }^{3}$. Thus, disease prevalence of NTDs varies with respect to different genetic origin and the level of nutrition. In global terms this is evident from available figures in countries such as Japan where the prevalence at birth is extremely low (0.5 per thousand births), to other countries such as Ireland and Scotland where, at its height, the prevalence was 7 per 1000 births $^{4}$. Even within the EU, the prevalence varies from country to country. In addition there has been a significant reduction in most countries across Europe in recent years. While some of this is due to increasing availability of prenatal diagnosis and pregnancy termination, there also appears to have been a real reduction. This reduction preceded the discovery that folic acid could prevent the majority of NTDs and is difficult to explain. The prevalence at birth of NTDs is monitored in several centres throughout the EU and is reported in the Eurocat Register ${ }^{5}$.

\section{(b) Identification of the major risk factors involved}

Historically the risk factors for NTDs were on the one hand familial, suggesting a strong genetic component and on the other hand environmental. In the former category, the strongest risk factor was a mother having had a previously affected pregnancy. A first time NTD birth was called an occurrence. After such a birth the chance of a woman having a further affected birth, a recurrence, increased her risk to between ten and twenty fold the risk which pertained in that particular community. Such an increase would indicate that the genes passed to the embryo by the mother and the father were major factors. Other evidence supporting a genetic involvement was the higher rates in certain ethnic groups, even after migration to different countries, such as Irish emigrants to Australia. A higher prevalence has also been found in monozygotic compared to dizygotic twins ${ }^{4}$.

Early support for the involvement of a nutrient or nutrients as risk factors came from an increase in prevalence in the aftermath of periods of nutritional deprivation, such as the American Depression or the 'Dutch Famine' before the close of the Second World War $^{4}$. As discussed in later sections a series of intervention trials and case control studies have now identified folic acid/folate as being the major nutrient involved. This nutrient can prevent three quarters of NTDs if taken periconceptionally.

\section{Secular trends in EU disease pattern}

When it became clear about ten years ago that maternal periconceptional folic acid could prevent the majority of $\operatorname{NTDs}^{6,7}$. it was anticipated that efforts to increase intake of folic acid/folate would quickly lead to a dramatic reduction in prevalence. In retrospect this widely held belief was perhaps naive and it certainly has not happened to any significant extent. The recommendations set out by Public Health authorities may have contributed to this failure. The initial advice was that the desired increase of $400 \mu \mathrm{g}$ per day in folate/folic acid intake could be achieved in any one of three ways; i.e. increased intake of (a) foods rich in folate; (b) foods fortified with the synthetic form of the vitamin folic acid; (c) the taking of supplements that contain folic acid.

Option (a) was never realistic because there was no particular food apart from animal liver, that was sufficiently dense in folate that an increase of the order of $400 \mu \mathrm{g}$ could be achieved by any practical dietary change. Also, natural folates are very unstable compared to the synthetic form, folic acid. They are found as conjugates in nature which reduces their bioavailability to at least half that of folic acid.

By contrast folic acid, either taken in supplements or in fortified foods is extremely stable and totally bioavailable. It is thus able to dramatically increase folate status under circumstances where the equivalent increase in intake of food folate has little effect ${ }^{8}$. However, the most important and still the most enduring problem in communities availing of the opportunity to use folic acid to prevent NTDs is that approximately half of pregnancies are unplanned. This, coupled with the difficulty of getting the concept across to the public and getting compliance even in those who plan their pregnancies, has produced a situation where only a small number of women take folic acid periconceptionally. Estimates place this at less than one quarter and there is general agreement that folic acid prevention of NTDs, while feasible, has not happened ${ }^{9,10}$. In an effort to redeem this, the U.S. government has passed legislation to the effect that all flour in the U.S. will be fortified with folic acid. A low level was chosen, because of fear of exposure of other non-risk groups to excess folic acid, but a mean increase of $100 \mu \mathrm{g} / \mathrm{d}$ in the average U.S. diet was expected. While this level is less than the target of $400 \mu \mathrm{g}$ /day suggested to prevent NTDs, it is likely to be effective in preventing many NTDs in the U.S. ${ }^{11}$ Indeed, recent evidence suggests that this intervention has had a dramatic effect on folate status in the U.S. population. In a sample group the percentage of subjects with low plasma folates $(<3 \mu \mathrm{g} / \mathrm{L})$ was reduced from $20 \%$ to $1.7 \%{ }^{12}$.

It should be noted that there are negative aspects to food fortification. Masking of vitamin B12 deficiency anemia is a potential problem. Vitamin B12 deficiency occurs relatively commonly in elderly people. Folic acid supplementation or food fortification could prevent symptoms of anemia caused by vitamin B12 deficiency and allow the associated, often irreversible, neurologic damage to progress. Thus, if food fortification were to become widespread, it would be important to monitor 


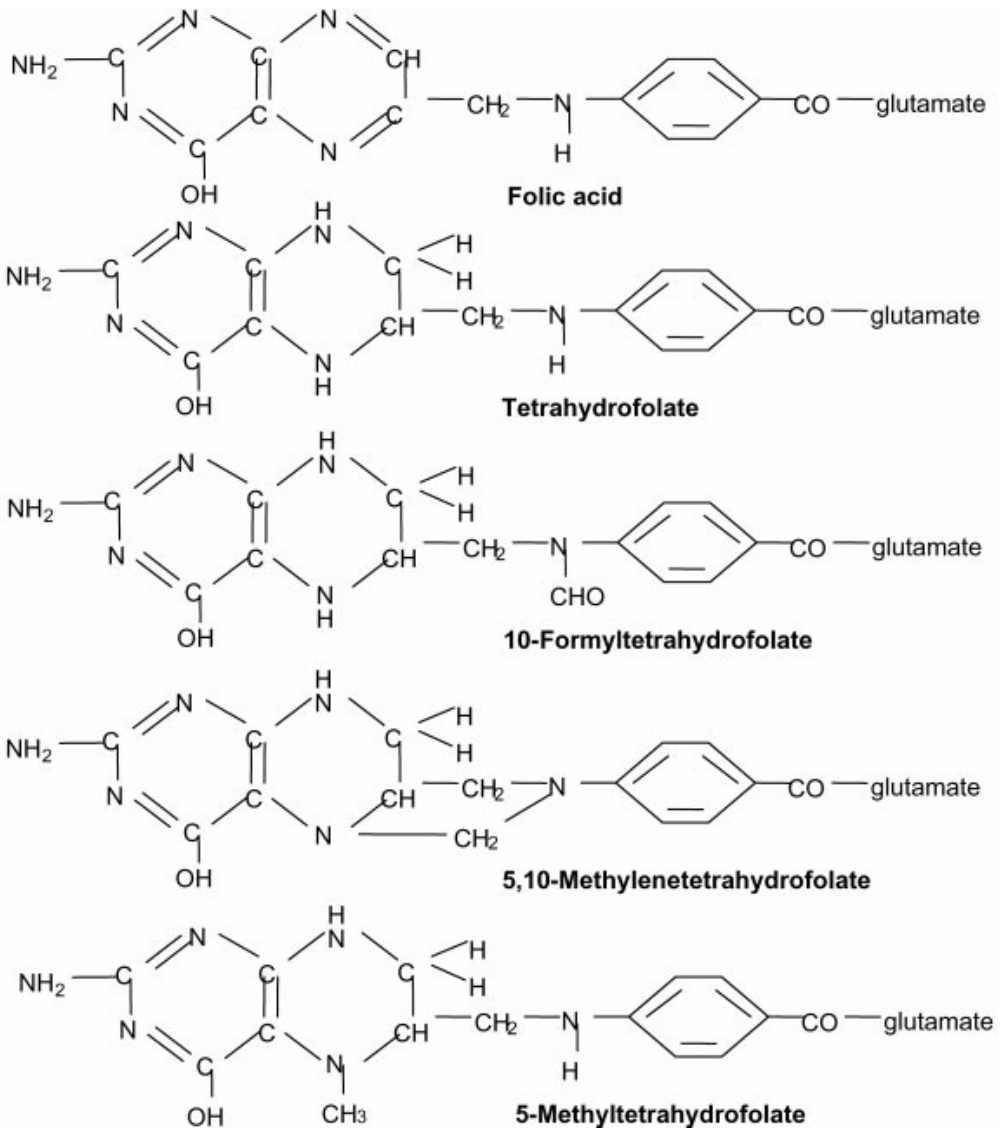

Fig. 1 The chemical formulae of the principal naturally occurring folate and of the synthetic form of the vitamin (folic acid)

B12 levels carefully in order to address this important public health issue.

\section{Patbogenic mechanisms}

It is clear that nearly three quarters of NTDs can be prevented by folic acid and it seems reasonable that the mechanism is by overcoming one or more genetically inherited metabolic blocks in folate dependent enzymes. The quarter of NTDs not prevented by folic acid are either not related to folate metabolism or are extremely intractable to treatment since they failed to respond to the very large dose of $4.0 \mathrm{mg} /$ day in the MRC trial ${ }^{6}$. The three quarters that did respond to folic acid are thought to be due to metabolic blocks in folate dependent enzymes. In fact one such gene has been identified, that which codes for the enzyme 5, 10 methylenetetrahydrofolate reductase (MTHFR). A polymorphism in this gene (C677T) is extremely common, having a homozygous prevalence of between 6 and 16\% in different communities $^{13}$. In one population it has been shown to account for $12 \%$ of the population attributable risk ${ }^{14}$. This suggests that there may be other folate related genes, as yet unidentified, that account for the remaining 60\% of the folic acid preventable NTDs. However, while the reduction of NTDs with folic acid has been firmly established (see below), nothing is known about the exact pathogenic mechanism.

In nature, folates are found with the pteridine ring reduced to tetrahydrofolate, unlike the synthetic form folic acid (Fig. 1). These reduced folates are involved in the transfer of one-carbon groups in purine and pyrimidine biosynthesis and in the methylation of a wide range of biologically important molecules. (Fig. 2). Folate functions in two major cycles. One of these (the DNA Synthesis Cycle) is essential for purine and pyrimidine biosynthesis and thus cell division (Fig. 2). It would be easy to see how any reduction in the capacity to maintain cell division at an optimum rate might compromise the closure of the rapidly developing neural tube. However, folate is also necessary to supply methyl groups to the Methylation Cycle (Fig. 2). This cycle provides methyl groups in the form of AdoMet to dozens of different methyltransferase enzymes present in all cells ${ }^{2}$. These involve the methylation of receptors, lipids, structural proteins, DNA, etc. Methylation of DNA is one of the principle methods of down regulating gene expression $^{15}$. Since neural development is achieved by switching on and off a sequence of genes in a precise order and time frame, it is easy to see how a reduction in the efficiency of this cycle could cause NTDs. 


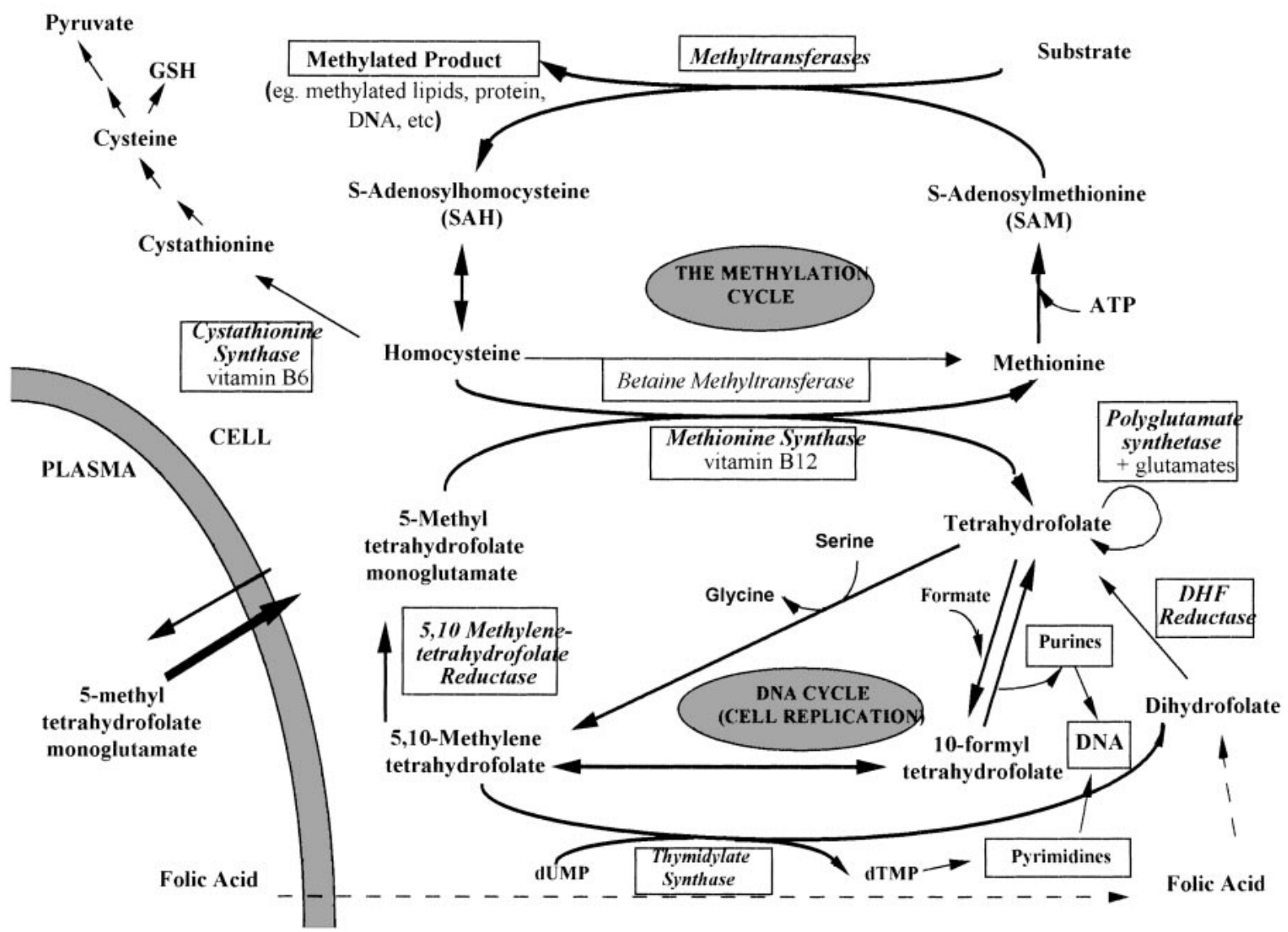

Fig. 2 The principal biochemical pathways in which the folate cofactors function

\section{Dose response relationships}

The double blind placebo controlled intervention trial carried out by the U.K. MRC to prevent NTD recurrence used $4.0 \mathrm{mg} / \mathrm{d}^{6}$. The only double blind trial to prevent occurrence used $800 \mu \mathrm{g} / \mathrm{d}^{7}$. However, earlier intervention recurrence trials done by Smithells and his colleagues ${ }^{16,17-}$ seemed to indicate that $400 \mu \mathrm{g} / \mathrm{d}$ was effective. In support of this lower dose, a large number of case/ control studies showed that women, who took folic acid supplements, usually at the level of $400 \mu \mathrm{g} /$ day, had a dramatic reduction in prevalence ${ }^{3}$. It had been found by Daly et $a l^{18}$ that maternal red blood cell folate levels of greater than $400 \mu \mathrm{g} / \mathrm{L}$ were associated with low risk of NTDs. A subsequent placebo controlled intervention trial in young women showed that daily supplements of $200 \mu \mathrm{g}$ folic acid/day could achieve such red cell folate levels and perhaps supplements as low as $100 \mu \mathrm{g} /$ day might be effective if taken habitually ${ }^{11}$.

\section{Preventability}

Unlike in the case of most nutrients and their effect on different clinical conditions, the evidence that folic acid can prevent the majority of NTDs is not really in any doubt. (a) Intervention studies

Earlier intervention studies by Smithells and his colleagues ${ }^{16,17}$ strongly suggested that over half, possibly three quarters, of NTDs could be prevented by maternal periconceptional ingestion of folic acid. However these interventions were not double blind, and they did not have a placebo group. In addition they used a multivitamin preparation (Pregnavite Forte F) that contained several vitamins and trace elements as well as folic acid at $360 \mu \mathrm{g}$ dosage/day. Pregnancies where supplements were taken had a marked reduction in the prevalence of NTDs when compared to pregnancy outcomes where for one reason or another the mother had not entered the study. Concern was expressed that these latter women were intrinsically different. Smithells et $a l^{17}$ argued persuasively that analysis of these mothers with respect to age, social class etc. compared to those taking the supplement showed no differences. However, many experts were not convinced that a firm conclusion could be drawn with respect to the effectiveness of the supplement. The first publication of Smithells' group ${ }^{16-}$ prompted Laurence et al. ${ }^{19}$ to revisit a small placebo controlled trial using high dose $(4.0 \mathrm{mg}$ /day) folic acid to prevent NTDs. This trial was negative in that two of the women in the treatment group had NTD affected births. 
One of these women later admitted that she had not been taking the folic acid while the other woman with an affected pregnancy had the least raised plasma folate levels of all of those on folic acid. On the basis of this information, Laurence et al. ${ }^{19}$ transferred both of these women to the non treatment group and the result became significant. Most observers consider this to be invalid.

Finally in August 1991, the results of a placebo controlled double blind trial conducted under the auspices of the United Kingdom MRC showed conclusively that periconceptional intervention with folic acid reduces the risk of NTD recurrence ${ }^{6}$. This was followed shortly by a trial that examined the effect of a multivitamin preparation in preventing occurrence of NTDs ${ }^{7}$. The trial was large but because it was on women who had no history of an affected birth (i.e. it investigated occurrence) the number of NTDs in the control group was only six, because of the lower risk of NTDs in such pregnancies. However there were no affected births in the women taking the multivitamin preparation. These intervention studies led the U.K. and U.S. Governments to recommend $4.0 \mathrm{mg}$ and $400 \mu \mathrm{g}$ of folic acid daily to prevent recurrence and occurrence of NTDs respectively ${ }^{20,21}$.

\section{(b) Cohort Studies}

While the trials described above were in progress and being reported, a large number of case/control studies began to appear. With one exception, all of these studies found a lower prevalence of NTDs in women who were taking supplements that contained folic acid around the time of conception compared with those who were not ${ }^{22}$. While these studies were not of themselves conclusive, when taken in conjunction with the intervention trials they were helpful. Firstly they confirmed that occurrence as well as recurrence could be prevented by folic acid. Secondly, most of the supplements in use contained $400 \mu \mathrm{g}$ folic acid thus adding confidence to the recommendation that the low level of $400 \mu \mathrm{g}$ /day would be effective in preventing NTDs even though the successful trial by Czeizel and Dudas ${ }^{7}$ had used $800 \mu \mathrm{g} /$ day.

\section{Conclusions}

Maternal ingestion of folic acid prior to and during the early weeks of pregnancy prevents perhaps up to three quarters of NTDs. Using this result to develop a successful Public Health policy has been largely unsuccessful for two reasons. In most countries up to half of pregnancies are unplanned. By the time women realise they are pregnant it is frequently after the 21 to 27 day period of closure of the neural tube after which point folic acid will have no protective benefit. Secondly, even in women who plan their pregnancies, it has proved very difficult to transmit to them in a convincing way the protective effect of folic acid and to obtain compliance in taking it on a regular basis, even in those who understand the benefits.

\section{Homocysteine and cardiovascular disease}

\section{The burden of disease}

(see other papers on cardiovascular disease (CVD) in this Supplement)

\section{Secular trends in EU disease patterns}

(see other papers on cardiovascular disease (CVD) in this Supplement)

\section{Patbogenic mechanisms}

The amino acid homocysteine is a normal constituent of plasma. It arises from the breakdown of the essential dietary amino acid methionine. Methionine is present in almost all diets to a large excess over requirements for protein biosynthesis ${ }^{1}$. This excess is degraded via AdoMet and s-adenosylhomocysteine (AdoHcy) to homocysteine (Fig. 2). At this point, the homocysteine can be catabolised to cystathionine. Further breakdown via cysteine to pyruvate and sulphate occurs mainly in the liver, with pyruvate being used for energy. Alternatively the carbon-sulphur skeleton can be preserved by being remethylated to methionine. Normally the level of homocysteine in cells and in the plasma is kept within very narrow limits. This is achieved by balancing its production via the 'methylation cycle' with its degradation by cystathionine synthase (CBS) and its conservation by methionine synthase (MS). Another enzyme is also involved, namely MTHFR, which is necessary to supply the methyl group required by methionine synthase in its methylation of homocysteine. This methyl group must be provided as the folate cofactor 5-methyltetrahydrofolate. While homocysteine does not normally become elevated in cells or in plasma, this is very dependent upon an adequate nutrient intake. This is because the three key controlling enzymes all require vitamins as cofactors. The enzyme CBS requires vitamin $\mathrm{B}_{6}$, MTHFR requires folate and $\mathrm{MS}$ requires both folate and vitamin $\mathrm{B}_{12}$. If there is even a modest reduction in the status of any of these three nutrients the plasma homocysteine level becomes elevated. Homocysteine is also remethylated by betaine methyltransferase, although this secondary pathway occurs mainly in the liver (Fig. 2). It has been recognised for a decade that plasma homocysteine is a useful biochemical marker to detect early or subtle reduction in the status of folate, vitamin $\mathrm{B}_{6}$ or vitamin $\mathrm{B}_{12}$. It has now emerged that any elevation of plasma homocysteine is an important independent risk factor for heart disease and stroke. There are several plausible ways in which elevated plasma homocysteine, which probably reflects an elevation in intracellular homocysteine, could increase the risk of cardiovascular disease. These four lines of evidence are reviewed in detail elsewhere ${ }^{23}$ but can be summarised as follows:

(a) Genetic mutations of the three enzymes which 
regulate the homocysteine level in cells and in the plasma, while relatively rare, have been well documented. Such mutations of MS, CBS or MTHFR are associated with premature death through heart disease or stroke. While individually they show very different biochemical profiles, they all have in common very high plasma homocysteine levels. It has been suggested that these high levels of homocysteine cause arterial and venous damage and consequent increased clinical risk in a manner as yet unclear $^{24}$.

(b) Retrospective case/control studies have compared the level of plasma homocysteine in patients who have either had a heart attack or a stroke, with matched controls who have no evidence of disease. These numerous studies all conclude that having such conditions is associated with elevated plasma homocysteine and that an increase of $5 \mu \mathrm{mol} / \mathrm{L}$ in plasma homocysteine was associated with a $60 \%$ increase in CVD among men [CI 40-70\%] and an 80\% increase [CI 30-90\%] in women ${ }^{25,26}$.

(c) While the above case/control studies are subject to misinterpretation because the clinical condition might be a cause rather than a result of the elevated plasma homocysteine, there are now at least fourteen prospective studies which have examined risk of CVD associated with elevated plasma homocysteine $^{26}$. Many (but not all) of these studies show a highly significant increased risk associated with any elevation of plasma homocysteine. This risk extended down to the lowest levels, and as with other established risk factors such as cholesterol, there was no threshold. Similar results were observed for stroke $^{27}$

(d) Two studies have shown that in apparently normal people there is a highly significant correlation between stenosis or thickening of the arteries and plasma homocysteine ${ }^{28,29}$.

There is speculation as to the pathogenic mechanism that might bring about such risk. Three main mechanisms are suggested ${ }^{30}$. These are (i) activation of the coagulation cascade; (ii) damage to endothelial cells and (iii) lipid peroxidation.

\section{Preventability}

Several studies now show that many apparently healthy normal individuals have plasma homocysteine levels that can be lowered by taking extra folic acid ${ }^{31}$. The level required is small and in the physiological range of an extra 100-200 $\mu \mathrm{g} /$ day. While reduced status of vitamin $\mathrm{B}_{6}$ or vitamin $\mathrm{B}_{12}$ are also associated with elevated plasma homocysteine, they appear to be less of a public health problem. Several studies have concluded that most people do not obtain any reduction in their homocysteine levels if given vitamin $\mathrm{B}_{6}$ other than a small decrease after a high challenge dose of oral methionine. Likewise while patients who are vitamin $B_{12}$ deficient benefit from vitamin $\mathrm{B}_{12}$ with respect to lowering plasma homocysteine, such cases are quite rare.

\section{Conclusions}

There are several lines of evidence leading to the conclusion that any elevation of plasma homocysteine is associated with increased risk of heart disease, premature vascular disease and stroke. Many experts in this field consider the present evidence to be convincing enough to recommend that plasma homocysteine should be reduced in all individuals where it is found to be elevated. Since this is much of the population, it would require fortification of a dietary staple food, such as flour, to be effective. There is however, a substantial body of expert opinion that such general or even individual intervention to lower plasma homocysteine is premature in advance of a double blind placebo controlled trial to show that such lowering does in fact reduce the prevalence of heart disease or stroke. There are world-wide more than ten large scale trials presently testing this hypothesis. However, since it is apparent from a number of studies that in any particular individual, amounts of folic acid found in over-the-counter supplements reduced plasma homocysteine to its lowest base-line level, it is difficult to see such trials succeeding. The present trials may have to last three to five years to act as a reasonable test of effectiveness, considering that this was the time-frame necessary to show effectiveness of lowering plasma cholesterol through drug intervention. However, these cholesterol trials involved drugs not readily available to the general public. It is difficult to envisage a participant, having been informed of the evidence of homocysteine and cardiovascular disease, being prepared to take the risk of being in the placebo arm of such a trial, when folic acid is so effective and so readily available. This would be particularly true if the trial was one of secondary prevention i.e. seeking to recruit and keep compliant patients with a previous history of heart disease or stroke.

\section{Folates and cancer}

\section{The burden of disease}

(see other papers on cancer in this Supplement)

\section{Secular trends in EU disease patterns}

(see other papers on cancer in this Supplement)

\section{Patbogenic mechanisms}

Two principle mechanisms whereby marginal or inadequate folate status might increase the risk of cancer have been proposed.

(1) It is suggested that such reduced status might diminish the capacity of replicating cells to synthesize 
sufficient thymidine for DNA biosynthesis. The conversion of deoxyuridine to deoxythymidine is achieved in cells through the enzyme thymidylate synthase which converts deoxyuridine monophosphate into deoxythymidine monophosphate. The cofactor needed for this reaction is 5,10 methylenetetrahydrofolate. It is suggested that with reduced folate status there might be accumulation of deoxyuridine with its consequent incorporation as the corresponding triphosphate into DNA. The resulting DNA containing the uracil rather than the usual thymine base is suggested to increase the risk of miscoding and ultimately cause the emergence of malignant cells ${ }^{32}$.

(2) The folate cofactors are needed to maintain an adequate supply of the methyl donor AdoMet in cells (Fig. 2). As noted above, at least thirty different methyltransferases have been identified. These enzymes, as the name suggests, add a methyl group to a wide range of substrates. The methyl group is provided through AdoMet. The product of the reaction is AdoHcy which is a potent inhibitor of all methyltransferase enzymes. Normally, AdoHcy is removed by being hydrolysed to homocysteine and adenosine. However, if there is impaired folate status, the cellular and plasma levels of homocysteine become elevated. Elevation of intracellular homocysteine in turn causes an elevation of AdoHcy and inhibition of methyltransferase reactions. Such inhibition could prevent the methylation of DNA and thus prevent down regulation of gene expression. It is suggested that this might cause hyperplasia and ultimately cancer ${ }^{33}$.

\section{Preventability}

The role of folate status as a contributor to overall cancer risk is clearly very complicated. In animal studies, diets deficient in methyl groups (choline, methionine and folate) were shown to increase the development of spontaneous hepatocarcinoma ${ }^{34}$. Some early studies, which claimed that hyperplastic growth in the lung and cervix could be reduced by extra folic acid, were not eventually substantiated. However, interest in folic acid/ folate in colorectal cancer has been maintained and recently enhanced ${ }^{33,34}$. Epidemiological evidence suggests that foods containing vegetables taken at moderate to high levels reduce the prevalence of colorectal and other cancers. Such foods could be anticipated to be high in folates. However they would also have a high content of other nutrients thought to reduce cancer risk, such as the antioxidant vitamins and would contribute to increasing dietary fibre. Thus, until relatively recently, the evidence that folic acid/folate could prevent or reduce the prevalence of colorectal cancer in man was weak.
However, recently a study providing direct evidence of prevention has been published.

Giovannucci et $a l .{ }^{35}$ examined the prevalence of colorectal cancer in 88,756 women who were part of the ongoing Nurses Health Study. Setting the baseline risk as that for women who did not take vitamins, they examined the effect of taking vitamins containing folic acid on reduction of risk (RR). Short term taking of vitamins (1-4 years) had no effect (RR 1.02). There was a small effect after 5-9 years (RR 0.83) and 10-14 years (RR $0.80)$. However for periods longer that 14 years there was a highly significant reduction (RR 0.25 : C1 0.13 to 0.51 ). While many of the women took other nutrients as well as folic acid, the authors concluded that the effect was largely due to the latter. The use of this and similar cohorts of health professionals has been criticized in the past because of bias in their selection. However, the demonstration that the reduction in risk was correlated with duration of vitamin intake, as one would expect biologically, acted as an internal control for the study.

\section{Conclusions}

The possibility that long-term folic acid supplementation at the level of $400 \mu \mathrm{g} /$ day can reduce risk of colorectal cancer by roughly $75 \%$ is extremely provocative. However, lot more research is needed in this complex area.

\section{Alzheimer's, Dementia and other neurological conditions}

\section{The burden of disease}

(see other papers on mental health in this supplement)

\section{Secular trends in EU}

(see other papers on mental health in this supplement)

\section{Patbogenic mechanisms}

There has long been thought to be an association between folate status and various mental disorders. These claims are based largely on the observations that many patients with various forms of mental illness have a poor folate status, as determined by their red cell or plasma folate levels ${ }^{36}$. However, many experts believe that such patients often have a poor diet and it is hard to determine if the poor folate status is cause or effect. Several studies have claimed improvement in various forms of mental function as a result of supplementation with folic acid ${ }^{36}$. However, many of these interventions were not well controlled and the assessment of the clinical improvement was often difficult to interpret. Nevertheless, some plausible pathogenic mechanisms have been suggested, the most attractive of these being the involvement of folates in maintaining an adequate supply of methyl groups for the many methylation reactions which are essential in maintaining normal brain metabolism and function. 
Alzheimer's Disease has recently been shown to be associated with elevated plasma homocysteine ${ }^{37}$. It is suggested that this is due to low folate status and there is ample general evidence for such a correlation, as discussed earlier. A pathogenic mechanism has been proposed to the effect that elevated plasma homocysteine could progressively cause small clots in the microvasculature of the brain ${ }^{37}$. These areas of resultant hypoxia could then be susceptible to the accumulation of the plaques which are characteristic of the disease. However, much more research is needed in this area to convince the scientific community that poor folate status with its accompanying raised plasma homocysteine is a cause rather than a result of Alzheimer's Disease.

\section{Preventability}

While several studies have shown associations between low folate status and poor mental health, there is, as yet, no good objective evidence that an improved or high folate status can prevent the development of these conditions.

\section{Conclusions}

Further proof of the detrimental effects of poor folate status on the development of mental ill health or Alzheimer's Disease is urgently required. If a causal relationship can be established, it would be very easily rectified through general fortification of a principle commodity of the diet such as flour with folic acid as has already been implemented in the U.S. to prevent neural tube defects.

\section{References}

1 Scott JM, Weir DG. Folate/Vitamin $\mathrm{B}_{12}$ inter-relationships. In: Tipton KF, ed. Essays in Biochemistry. Vol 28. London: Portland Press, 1994: 63-72.

2 Scott JM. Folate and vitamin $B_{12}$. Proc. Nutr. Soc. 1999; 58 : $441-8$.

3 Scott JM, Weir DG, Molloy A, McPartlin J, Daly L, Kirke P. Folic acid metabolism and mechanisms of neural tube defects. In: Bock G, Marsh J, eds. Ciba Foundation Symposium 181, Neural Tube Defects. Chichester: John Wiley and Sons, 1994: 180-91.

4 Elwood JM, Little J, Elwood JH. Epidemiology and control of neural tube defects. Oxford: Oxford University Press, 1992.

5 EUROCAT Working Group. Prevalence of neural tube defects in 20 regions of Europe and the impact of prenatal diagnosis, 1980-1986. J. Epidemiol. Community Health 1991; 45: 52-8.

6 MRC Vitamin Study Research Group. Prevention of neural tube defects: results of the Medical Research Council Vitamin Study. Lancet 1991; 338: 131-7.

7 Czeizel AF, Dudas J. Prevention of the first occurrence of neural tube defects by periconceptional vitamin supplementation. New Engl. J. Med. 1992; 327: 1832-5.

8 Cuskelly CJ, McNulty H, Scott JM. Effect of increasing dietary folate on red-cell folate: implications for prevention of neural tube defects. Lancet 1996; 347: 657-9.

9 Scott JM, Weir DG, Kirke PN. 'Prevention of neural tube defects with folic acid a success but...' Q. J. Med. 1994; 87: $705-7$.
10 Daly S, Scott JM. The prevention of neural tube defects. Curr. Opin. Obstet. Gynecol. 1998; 10: 85-9.

11 Daly S, Mills JL, Molloy AM, Conley M, Lee YJ, Kirke PN, Weir DG, Scott JM. Minimum effective dose of folic acid for food fortification to prevent neural-tube defects. Lancet 1997; 350: $1666-9$

12 Jacques PF, Selhub J, Bostom AG, Wilson PW, Rosenberg IH. The effect of folic acid fortification on plasma folate and total homocysteine concentrations. New. Engl. J. Med. 1999; 340: 1449-54.

13 Schneider JA, Rees DC, Liu YT, Clegg JB. Worldwide distribution of a common methylenetetrahydrofolate reductase mutation [letter]. Am. J. Hum. Genet. 1998; 62: 1258-60.

14 Shields DC, Kirke PN, Mills JL, Ramsbottom D, Molloy AM, Burke H, Weir DG, Scott JM, Whitehead AS. The 'thermolabile' variant of methylenetetrahydrofolate reductase and neural tube defects: An evaluation of genetic risk and the relative importance of the genotypes of the embryo and the mother. Am. J. Hum. Genet. 1999; 64: 1045-55.

15 Bestor T. Methylation patterns in the vertebrate genome. $J$. Natl. Inst. Health Res. 1993; 5: 57-60.

16 Smithells RW, Sheppard S, Schorah CJ, Seller MJ, Nevin NC, Harris R, Read AP. Possible prevention of neural tube defects by periconceptional vitamin supplementation. Lancet 1980; i: $339-40$.

17 Smithells RW, Nevin NC, Seller MJ, Sheppard S, Harris R, Read AP, Fielding DW, Walker S, Schorah CJ, Wild J. Further experience of vitamin supplementation for prevention of neural tube defect recurrences. Lancet 1983; i: 1027-31.

18 Daly LE, Kirke PM, Molloy A, Weir DG, Scott JM. Folate levels and neural tube defects. Implication for prevention. JAMA 1995; 274: 1698-702.

19 Laurence KM, James N, Miller MH, Tennant GB, Campbell H. Double blind randomised controlled trial of folate treatment before conception to prevent recurrence of neural-tube defects. Br. Med. J. 1981; 282: 1509-11.

20 Expert Advisory Group. Folic acid and the prevention of neural tube defects. London: Department of Health, 1992.

21 Centers for Disease Control. Recommendations for the use of folic acid to reduce the number of cases of spina bifida and other neural tube defects. MMWR 1992; 41: 1-7.

22 Scott JM, Weir DG, Kirke PN. Folate and neural tube defects. In: Bailey LB, ed. Folate in Health and Disease. New York: Marcel Dekker, Inc., 1995: 329-60.

23 Weir DG, Scott JM. Homocysteine as a risk factor for cardiovascular disease: nutritional implications. Nutr. Res. Rev. 1998; 11: 311-38.

24 McCully KS. Vascular pathology of homocysteinemia: implications for the pathogenesis of arteriosclerosis. Am.J. Pathol. 1969; 56: 111-28.

25 Boushey CJ, Beresford SA, Omenn GS, Motulsky AG. A quantitative assessment of plasma homocysteine as a risk factor for vascular disease: probable benefits of increasing folic acid intake. JAMA 1995; 274: 1049-57.

26 Eikelboom JW, Lonn E, Genest J, Hankey G, Yusuf S. Homocysteine and cardiovascular disease: A critical review of the epidemiologic evidence. Ann. Intern. Med. 1999; 131: 363-75.

27 Perry IJ, Refsum H, Morris RW, Ebrahim SB, Ueland PM, Shaper AG. Prospective study of serum total homocysteine concentration and risk of stroke in middle-aged British men. Lancet 1995; 346: 1395-8.

28 Selhub J, Jacques PF, Bostom AG, D'Agostino RB, Wilson PW, Belanger AJ, O'Leary DH, Wolf PA, Schaefer EJ, Rosenberg IH. Association between plasma homocysteine concentrations and extracranial carotid-artery stenosis. N. Engl.J. Med. 1995; 332: 286-91.

29 Malinow MR, Nieto FJ, Szklo M, Chambless LE, Bond G. Carotid artery intimal-medial wall thickening and plasma 
homocyst(e)ine in asymptomatic adults: The Atherosclerosis Risk in Communities Study. Circulation 1993; 87: 1107-13.

30 Green R, Jacobsen DW. Clinical implications of hyperhomocysteinaemia. In: Bailey LB, ed. Folate in Health and Disease. New York: Marcel Dekker, Inc., 1995: 75-122.

31 Homocysteine Lowering Trialists' Collaboration. Lowering blood homocysteine with folic acid based supplements: meta-analysis of randomized trials. BMJ 1998; 316: 894-8.

32 Blount BC, Mack MM, Wehr CM, MacGregor JT, Hiatt RA, Wang G, Wickramasinghe SN, Everson RB, Ames BN. Folate deficiency causes uracil misincorporation into human DNA and chromosome breakage: implications for cancer and neuronal damage. Proc. Natl. Acad. Sci. USA 1997; 94: 3290-5.

33 Choi SW, Mason JB. Folate and carcinogenesis. J. Nutr. 2000; 130: $129-32$.
34 Mason JB. Folate Status: Effects on Carcinogenisis. In: Bailey LB, ed. Folate in Health and Disease. New York: Marcel Dekker, Inc., 1995: 361-78.

35 Giovannucci E, Stampfer MJ, Colditz GA, Hunter DJ, Fuchs C, Rosner BA, Speizer FE, Willett WC. Multivitamin use, folate and colon cancer in women in the Nurses' Health Study. Ann. Intern. Med. 1998; 129: 517-24.

36 Bottiglieri T, Crellin RF, Reynolds EH. Folates and Neuropsychiatry. In: Bailey LB, ed. Folate in Health and Disease. New York: Marcel Dekker, Inc., 1995: 435-62.

37 Clarke R, Smith AD, Jobst KA, Refsum H, Sutton L, Ueland PM. Folate, vitamin $B_{12}$ and serum total homocysteine levels in confirmed Alzheimer Disease. Arch. Neurol. 1998; 55: $1449-55$. 